\title{
Empresa familiar, sim! Mas qual o problema, se a gestão é profissional?
}

\section{RESUMO}

Este artigo visa contribuir para melhor compreensão da realidade de uma empresa familiar brasileira em fase de transição do seu modelo de gestão familiar para uma gestão profissionalizada. A empresa estudada é uma livraria brasileira de pequeno porte, fundada em 2000, no interior do estado do Rio de Janeiro, atualmente com seis lojas próprias e outra franqueada, totalizando quarenta funcionários. Sua administração, basicamente familiar, necessita de um novo modelo de gestão para acompanhar o ritmo de sua expansão. O método de pesquisa adotado foi o estudo de caso, com a coleta de dados por meio de entrevistas semiestruturadas com os gestores da empresa. Os principais resultados mostraram que, embora a empresa esteja em processo inicial de profissionalização, precisa, no entanto, acelerar esse processo, adotando uma postura proativa que dê suporte ao seu crescimento.

Palavras-chave: Pequena empresa. Empresa familiar. Profissionalização.

Alicelia Rosa de Oliveira Pecanha aliceliaoliveira@gmail.com Universidade Federal Rural do Rio de Janeiro (UFRRJ)

Saulo Barbara de Oliveira saulobarbara@gmail.com Universidade Federal Rural do Rio de Janeiro (UFRRJ) 


\section{INTRODUÇÃO}

Para compreensão do presente estudo, faz-se necessário, inicialmente, conceituar empresa familiar, analisar suas características, peculiaridades, forças e fraquezas no âmbito da gestão.

Neste artigo, o objetivo foi investigar uma empresa familiar de médio porte à luz do referencial teórico e estabelecer relações sobre as suas características e estilo de gestão com o que prescreve a literatura pesquisada.

A justificava para a pesquisa foi investigar se o processo de gestão e as principais características das empresas familiares, comumente apostados na literatura, estão dificultando o crescimento e expansão, tão desejados, na empresa estudada e, com base nas descobertas, propor um encaminhamento visando contribuir para superação das possíveis dificuldades.

Para isso, os autores lançaram mão de uma pesquisa qualitativa e exploratória, com foco no método de estudo de caso.

O artigo foi organizado da seguinte forma: na primeira parte da pesquisa consta a introdução, o cenário da empresa e a questão pesquisada. Na segunda encontra-se o referencial teórico, no qual são abordados temas relacionados à empresa familiar e à profissionalização da gestão. Na terceira parte, está o embasamento metodológico, com a fundamentação sobre os métodos escolhidos para a realização da pesquisa, seguidos pela apresentação dos resultados, discutidos à luz do referencial teórico. Por último, são feitas as considerações finais.

\section{EMPRESA FAMILIAR}

A literatura a respeito do tema pesquisado possibilita observar algumas divergências entre os autores acerca do significado de empresas familiares, embora o referido conceito encontre um bom amparo na literatura, como o de Donnelley (1967), que se refere à empresa familiar como aquela que conserva o vínculo com uma mesma família durante pelo menos duas gerações e na qual a relação empresa/família exerce influência tanto sobre as diretrizes empresariais como sobre os interesses e objetivos da família.

Dailey et al. (1997) classificam como empresa familiar aquela na qual o vínculo com a família exista há pelo menos uma geração mediante uma relação dinâmica entre os membros da família e os executivos da empresa, de forma a exercer forte influência sobre a política da empresa. Já segundo Barry (1978), o controle acionário da empresa por uma única família é considerado a principal condição para que uma empresa seja definida como familiar, seja ela de capital fechado ou aberto. Lodi (1998) concorda com o conceito de Donnelley (1967), quando diz que o que define uma empresa familiar é a influência recíproca entre a família e a firma. Oliveira $(1999$, p. 18) acentua esse conceito ao afirmar que "[...] a empresa familiar caracteriza-se pela sucessão do poder decisório de maneira hereditária a partir de uma ou mais famílias". Contudo, a expressão "familiar" deixa implícito que há envolvimento de dois ou mais membros de uma família na vida da empresa, seja como proprietário, seja como administrador (GRZYBOVSKI; LIMA, 2004).

Uma das conceituações mais utilizadas para se considerar uma empresa familiar está relacionada à questão da propriedade. No entendimento de Gonçalves (2000), por exemplo, uma empresa familiar é definida com base na coexistência de três situações: a empresa é de propriedade de uma família; a família é a responsável pela estratégia da organização; e a família também é responsável pela administração do empreendimento, com a participação de membros familiares na diretoria da empresa. Litz (1995) considera que uma empresa familiar pode ser conceituada com base no grau de envolvimento de uma família empresária na propriedade e na gestão da organização. Gersick (1997) igualmente segue essa perspectiva, expressa no modelo amplamente difundido dos três círculos propriedade, empresa, família -, que constituem subsistemas independentes, porém, sobrepostos.

Desse modo, pode-se também conceituar empresa familiar fundamentando-se na interação das dimensões da propriedade, da empresa e da família, existentes no âmbito da organização. A interação entre família e empresa, explicitadas pela perspectiva da propriedade, constitui o principal elemento de distinção entre empresas familiares e não familiares.

Com efeito, essa interação tem sido reconhecida como um dos principais elementos constituintes e influenciadores da dinâmica das empresas familiares (DYER JR., 2009). Tal interação conduz à constituição de um tipo singular de organização, na medida em que estão presentes elementos econômicos e sociais no âmbito de uma estrutura organizacional e na medida em que essa interação exerce influência significativa sobre o desempenho e a sobrevivência da organização familiar (DYER JR., 2009).

De certo modo, no âmbito de uma empresa familiar, é comum que os objetivos e princípios 
organizacionais confundam-se com os valores cultivados na família. O equilíbrio entre os interesses individuais e/ou familiares e os objetivos organizacionais parece constituir a chave para a sobrevivência das organizações familiares (TILLMANN; GRZYBOVSKI, 2005).

Bernhoeft (1989) afirma que, quando o fundador responsabiliza-se pela gestão da organização, existem alguns traços que se destacam: a valorização dos funcionários antigos, principalmente os que começaram com o fundador; a provisão de cargos, promoções e premiações geralmente seguem critérios de confiança, lealdade e antiguidade dos trabalhadores, em detrimento da produtividade ou até mesmo da qualidade desse serviço; influência de laços afetivos nos comportamentos, relacionamentos e nas decisões empresariais; preferência pela comunicação verbal e contatos pessoais; exigência de dedicação ilimitada ao trabalho (sem horário fixo para sair, dispor dos fins de semana, levar tarefas para realizar em casa); vínculo exclusivo com a empresa; ambiguidade entre as decisões emocionais e as racionais; aplicação frequente de "jogos de poder", prevalecendo a habilidade política em detrimento da competência.

A literatura sobre o tema indica não haver uma definição de empresa familiar que seja completamente aceita e legitimada pelos teóricos do tema, ressaltando-se que muitas das características encontradas em empresas familiares podem também ser vistas em outras empresas, dificultando ainda mais a sua conceituação e demonstrando que o aspecto familiar está muito mais relacionado ao estilo com que a empresa é administrada do que apenas ao fato de seu capital pertencer a uma ou mais famílias (BERNHOEFT, 1989).

Barreto (2003) afirma que as empresas familiares geralmente desenvolvem relacionamentos mais informais, seja no âmbito interno, seja externo. Tal fato é percebido pelo mercado, fazendo com que clientes e fornecedores depositem sua confiança em razão da possibilidade de concretizar negócios com os membros da família proprietária.

Nesse contexto, o fundador desempenha papel relevante na trajetória da empresa, pois nela projeta suas crenças e seus valores, estabelecendo a missão da organização, definindo objetivos pretendidos e delimitando a rota, o caminho para a empresa seguir, bem como as metas que pretende alcançar no longo prazo.

Lodi (1998) ressalta que há alguns conflitos de interesses entre família e empresa, destacando quatro problemas frequentes: (1) uso indevido dos recursos da empresa por seus membros; (2) falta de sistemas de planejamento financeiro e de apuração de custo; (3) resistência à modernização; (4) emprego e promoção de parentes por favoritismo e não por competência.

O Quadro 1 ilustra a existência de múltiplas definições no que se refere ao conceito de empresa familiar no contexto da literatura vigente.

Quadro1 - Múltiplas definições de empresa familiar

\begin{tabular}{|c|}
\hline ela que, na prática, é controlada por uma única família (BARRY, 1999). \\
\hline $\begin{array}{l}\text { Empresa na qual os membros da família têm controle legal sobre a propriedade (LANSBERG; PERROW; } \\
\text { ROGOLSKY, 1988). }\end{array}$ \\
\hline $\begin{array}{l}\text { Empresa na qual uma só família possui a maioria do capital e tem o controle total. Os membros da família } \\
\text { formam parte da diretoria e tomam as decisões mais importantes (GALLO; SVEEN, 1991). }\end{array}$ \\
\hline Empresa que será transferida à geração seguinte da família para que a dirija e controle (WARD, 1999). \\
\hline $\begin{array}{l}\text { Organização na qual as principais decisões operacionais e os planos de sucessão da diretoria são influenciados } \\
\text { pelos membros da família que formam parte da diretoria ou do conselho de administração (HANDLER, 1989). }\end{array}$ \\
\hline $\begin{array}{l}\text { Empresa familiar é a que foi fundada por um membro da família e foi transmitida, ou espera-se que se } \\
\text { transmita, aos seus descendentes. Os descendentes do fundador ou fundadores originais terão a propriedade } \\
\text { e o controle da empresa. Além disso, membros da família trabalham e participam da empresa e dela se } \\
\text { beneficiam (BORK, 1986). }\end{array}$ \\
\hline
\end{tabular}

Fonte: Adaptado de Ribeiro (2008, p. 13)

\subsection{Forças e fraquezas das empresas familiares}

As empresas, especialmente as familiares, precisam identificar, ao longo da sua existência, suas forças e fraquezas, com vistas a minimizar os efeitos de suas fraquezas e promover-se por meio de suas forças identificadas (LODI, 1998).

Segundo Donnelley (1967), a presença de membros da família na gestão do negócio não pode ser considerada sinônimo de ineficiência e má administração, uma vez que a própria relação sanguínea pode ser capaz de promover maior comprometimento dos familiares com a organização. O quadro 2 evidencia as fraquezas e as vantagens presentes em empresas do tipo familiar. 
Quadro 2 - Fraquezas e vantagens das empresas familiares

\begin{tabular}{|l|l|}
\hline \multicolumn{1}{|c|}{ FRAQUEZAS } & \multicolumn{1}{|c|}{ VANTAGENS } \\
\hline $\begin{array}{l}\text { Conflitos entre os interesses da família e os da } \\
\text { empresa. }\end{array}$ & $\begin{array}{l}\text { Lealdade dos empregados, em virtude da } \\
\text { identificação com as pessoas. }\end{array}$ \\
\hline $\begin{array}{l}\text { Emprego e promoção de parentes por nepotismo, } \\
\text { em detrimento da qualificação profissional. }\end{array}$ & $\begin{array}{l}\text { Sensibilidade social e política, pela possível influência } \\
\text { da família nas relações nacionais e regionais. }\end{array}$ \\
\hline $\begin{array}{l}\text { Resistência à modernização da área comercial, } \\
\text { sujeitando-se a antigos vendedores de confiança. }\end{array}$ & Sistema de decisão mais rápido. \\
\hline $\begin{array}{l}\text { Falta de controle e planejamento de custos e recursos } \\
\text { fnanceiros. }\end{array}$ & $\begin{array}{l}\text { Maior humanismo nas relações e permanência por } \\
\text { causa das sucessões, dos valores fundacionais e } \\
\text { visões pessoais dos dirigentes. }\end{array}$ \\
\hline $\begin{array}{l}\text { Apropriação de recursos da organização para } \\
\text { membros da família. }\end{array}$ & $\begin{array}{l}\text { Continuidade do negócio, pela sucessão de familiares } \\
\text { capacitados e competentes. }\end{array}$ \\
\hline
\end{tabular}

Fonte: Elaboração própria com base em Lodi (1998)

\subsection{Traços culturais da empresa familiar}

As empresas familiares brasileiras possuem características que também devem ser exploradas, pois são traços da cultura nacional que se apoiam na gestão das organizações e são alvos constantes de estudos que abrangem a formação histórica, cultural e econômica do país. Tais traços interferem na gestão organizacional brasileira, sendo alguns deles destacados a seguir.

a) Jeitinho - Visa à harmonização das regras e determinações universais da vida com as necessidades diárias do cidadão, buscando a realização de objetivos a despeito de determinações legais contrárias. Conforme Barbosa (1992), o jeitinho é ambíguo e admite dupla leitura, podendo significar uma postura conformista de convivência com o status quo injusto e inaceitável; e podendo ser visto como uma forma de sobreviver ao cotidiano, um recurso de resistência cultural.

b) Desigualdade de poder e hierarquia - Pode ser percebida quando muitos indivíduos se julgam com direitos especiais que os eximem de sujeitar-se à lei de caráter generalizante. A expressão popular "você sabe com quem está falando?", citada por DaMatta (1981, p.167), é comumente ouvida em situações de conflito e revela uma reação autoritária, que tenta impor uma condição especial.

c) Flexibilidade - Permeia os comportamentos nas organizações e traduz-se na capacidade de adaptação e criatividade das pessoas. A adaptação refere-se à capacidade de ajuste a situações diversas, e a criatividade refere-se à capacidade de inovação.

d) Personalismo - Pode ser expresso pela importância atribuída às pessoas e aos interesses pessoais em detrimento das pessoas ou interesses do grupo ou comunidade. Indica o alto grau de confiança depositado na rede de amigos e familiares para resolução de problemas ou obtenção de privilégios.

e) Formalismo - Que é percebido nas organizações por meio de comportamentos que buscam por um lado a redução do risco, da ambiguidade e da incerteza e, por outro, o aumento de previsibilidade e controle sobre as ações e comportamentos humanos.

\section{PROFISSIONALIZAÇÃO DA GESTÃO FAMILIAR}

A profissionalização pode ser entendida como um processo de evolução em direção a um processo mais formalizado, podendo ser traduzida em termos do desenvolvimento da estrutura organizacional. O termo profissionalização parece estar inserido de forma tão normal no linguajar dos gestores, e em publicações a respeito do assunto, que, em virtude disso, merece uma definição.

A profissionalização é o processo pelo qual uma organização familiar ou tradicional assume práticas administrativas mais racionais, modernas e menos personalizadas; é a adoção de um determinado código ou de conduta num grupo de trabalhadores; é a substituição de métodos intuitivos por métodos impessoais e racionais; é a substituição de formas de contratação de trabalho arcaicas ou patriarcais por formas assalariadas (LODI, 1998, p. 25).

A conceituação de empresa profissionalizada, em muitos aspectos, aproxima-se ao de organização burocrática, descrita por Weber et al. (1982), sobretudo nos seguintes pontos: a prevalência do poder 
do administrador profissional sobre o administrador patrimonial; o predomínio da racionalidade funcional; a delimitação da autoridade e sua distribuição de forma estável; a exigência de qualificação para o emprego das pessoas; e a maior formalização e documentação das ações administrativas.

Para Bernhoeft (1989, p. 19), "[...] ao falarmos em profissionalização da empresa familiar é importante considerar que ela não se refere, exclusivamente, aos aspectos organizacionais", já que a mudança na estrutura deverá, obrigatoriamente, ser precedida pela conscientização daqueles que detêm a propriedade e o poder, da necessidade imperativa da separação entre a família, a propriedade e a gestão. É importante salientar que profissionalização da gestão não significa o afastamento dos membros da família e/ou da direção da empresa e sim de prevalência do critério da vocação e da competência entre os administradores escolhidos para gerir o negócio.

Partindo da visão funcionalista sobre profissionalização, que se orienta preponderantemente pelo desempenho organizacional, Sindhuja (2009) evidencia a superioridade da gestão profissional na criação de valor para a empresa sobre a gestão familiar.

Mesmo na literatura de orientação interpretativista (FREITAS, 1999), como na de orientação estruturalista (SCHEIN, 2004), os autores baseiam-se no fato de que, ao iniciar a organização, o fundador inauguraria as bases culturais norteadoras e seria um líder dos princípios e da cultura organizacional.

De acordo com Barroso (2011), a sucessão e a profissionalização em empresas familiares na literatura funcionalista, de uma forma em geral, focam em assuntos como a competência ou não dos gestores familiares em alcançar eficiência operacional ou uma vantagem competitiva sustentável, embora, especialmente nas empresas familiares, elementos subjetivos também estejam envolvidos nesses dois processos.

Barroso (2011) percebe que a sucessão e a profissionalização em empresas familiares são dois momentos delicados sob variados aspectos. A ruptura com os ideais e os valores familiares ou a luta pelo poder entre os herdeiros pode desencadear trajetórias conturbadas, tanto do ponto de vista econômico-financeiro, como do aspecto comportamental.

Hall e Nordqvist (2008) igualmente defendem a possibilidade de as empresas serem gerenciadas por familiares e alcançarem posição competitiva, pois que os familiares podem possuir competência formal semelhante aos gestores profissionais e superá-los na competência cultural, definida pelos autores como a compreensão dos valores e das normas que guiam o comportamento familiar nos negócios.

\section{METODOLOGIA}

A presente pesquisa é de natureza qualitativa e exploratória, conduzida por meio de um estudo de caso único. A classificação em qualitativa e exploratória está baseada no que propõe Minayo (2006). É exploratória, por se tratar de uma atividade básica da ciência sociais, a primeira realizada na empresa investigada, e qualitativa, uma vez que visou à construção da realidade, sem se preocupar com o que não pode ser quantificado, trabalhando com o universo de crenças, valores, significados e outros construtos profundos das relações que não podem ser reduzidos à operacionalização de variáveis.

A classificação como um estudo de caso único, encontra respaldo no que afirmam Voss, Tsikriktsis e Frohlich (2002), uma vez o objetivo nesta pesquisa foi retratar a história de um fenômeno atual, elaborada com base em evidências, que pode incluir dados de entrevistas sistemáticas, bem como da observação direta.

Buscou-se na empresa estudada, inicialmente, compreender o seu processo de gestão - incluindo suas principais características - a fim de tornar possível propor uma forma que pudesse dar o suporte necessário à sua expansão. Foram realizadas entrevistas semiestruturadas com os principais gestores e feita observação direta com o intuito de atender ao objetivo pretendido neste estudo.

\subsection{A empresa}

O estudo, conduzido de abril/2012 a abril/2014, aborda o caso de uma livraria de pequeno porte, fundada em 2000 e situada na cidade de Valença. Seu funcionamento, antes da delegação da gestão a um profissional iniciada em 2013, era gerido pelo proprietário e seu irmão, registrado como funcionário, e que atualmente é sócio da empresa. A empresa abrangia a demanda de atender ao mercado consumidor de 74 mil habitantes em Valença. Após quatorze anos, a empresa expandiu por 
meio de filiais, passando a atender também às cidades de Vassouras, Três Rios, Volta Redonda e Barra do Piraí, todas localizadas na região Sul Fluminense. A empresa possui quarenta colaboradores para atender a um mercado de cerca de 250 mil consumidores. Para isso, conta com uma rede de livrarias que faz uso de uma plataforma de comércio eletrônico (e-Commerce).

A organização nasceu e cresceu sob a ótica de gestão familiar e, para expandir sua rede, pretende que sua gestão seja totalmente profissionalizada. Como toda empresa familiar, ostenta como desafio adicional a necessidade de um equacionamento bem-sucedido da relação família e organização.

\section{ANÁLISE DOS RESULTADOS}

As empresas familiares geralmente desenvolvem relacionamentos mais informais, seja no âmbito interno, seja externo, e tal fato é percebido no mercado, fazendo com que clientes e fornecedores depositem sua confiança, em razão da possibilidade de concretizar negócios com os membros da família proprietária (BARRETO, 2003).

Nesse contexto, a pesquisa evidencia que o fundador da empresa estudada desempenha papel relevante na trajetória da empresa, pois nela projeta suas crenças e seus valores, estabelecendo a missão da organização, definindo objetivos pretendidos e delimitando a rota, o caminho para a empresa seguir, bem como as metas que pretende alcançar no longo prazo. Há também evidências de que os proprietários possuem a consciência de que o estilo de gestão da empresa é familiar, embora já adotem práticas profissionais preliminares na sua gestão, desde o início do ano de 2013.

Com base no que expôs Donnelley (1967), a presença de membros da família, na gestão do negócio, não pode ser considerada sinônimo de ineficiência e má administração, uma vez que a própria relação sanguínea pode ser capaz de promover maior comprometimento deles com a organização. Em virtude disso, há indicativos de que os gestores da empresa exigem dos familiares que atuam na organização a qualificação profissional para que possam enfrentar as questões competitivas exigidas pelo mercado e deixam claro que somente o fator sanguíneo não assegura a permanência na empresa.

Na pesquisa, foi possível observar que o nepotismo é um fator de incômodo para os entrevistados. Isso pôde ser notado pelo fato de que eles possuem uma irmã, que atua na empresa, que entrou na organização ainda menor de idade, e os proprietários exigem que ela se qualifique para que possa crescer e assumir um cargo de chefia na organização. Os gestores fazem questão de deixar claro ser esse um aspecto decisivo para a sua permanência na empresa.

Percebe-se que há uma valorização dos funcionários antigos, principalmente os que começaram com o fundador; um dos sócios atuais, anteriormente, foi funcionário da empresa, desde a sua inauguração. E corroboram com a afirmativa de Chu e Wood (2008) quando se posicionam em relação de que existe um alto grau de confiança depositado na rede de amigos e familiares para resolução de problemas ou obtenção de privilégios.

Quanto à provisão de cargos, promoções e premiações, as empresas familiares geralmente seguem critérios de confiança, lealdade e antiguidade dos trabalhadores, em detrimento da produtividade ou até mesmo da qualidade desse serviço. Porém, os gestores da empresa pesquisada promovem seus funcionários de acordo com a sua qualificação, mas não se baseiam somente em fatores como confiança, lealdade e antiguidade.

Nota-se que há a influência de laços afetivos nos comportamentos, relacionamentos e nas decisões empresariais na livraria, ficando bastante claro no relacionamento entre os irmãos gestores, que as decisões são tomadas em conjunto. Há cerca de um ano, os irmãos proprietários conscientizaram-se de que essa dependência prejudica a gestão e adotaram a postura mais livre para estratégias operacionais; entretanto, quanto a decisões estratégicas, ainda são dependentes um do outro.

A preferência pela comunicação verbal e contatos pessoais foi igualmente observada na pesquisa, pois os entrevistados afirmaram que gostam de olhar nos olhos dos funcionários, de se tratar com proximidade, de serem reconhecidos por funcionários de filiais de outras cidades. Este fato corrobora com o que pensa Bernhoeft (1989) ao destacar que a comunicação verbal é um traço dominante da gestão familiar.

Também foi constatado que, durante anos consecutivos, os gestores dedicaram-se por tempo ilimitado ao trabalho, sem horário fixo para sair, dispondo dos fins de semanas, levando tarefas para realizarem em casa, e que se conscientizaram que isso estava atrapalhando a qualidade da vida conjugal e familiar. Esse fato é também descrito por Bernhoeft (1989), ao apontar que este é 
um estilo de gestão caraterístico da empresa familiar. Contudo, os gestores da empresa pesquisada conseguiram reorganizar-se a fim de corrigir esse comportamento e racionalizar a rotina de trabalho.

Como esclarece Freitas (1999), os empreendedores tomam suas decisões baseadas no feeling, e esse traço cultural é tido como aventureiro e sonhador. Os gestores da empresa, ao serem questionados sobre esse tipo de comportamento, disseram ter seguido a mesma postura na inauguração de suas filiais; e que, ao olharem um ponto comercial vazio, já imaginavam que o local daria uma boa loja, confirmando que as suas pesquisas de mercado foram baseadas em "achismos".

Foi percebido também que houve uma grande resistência do proprietário em abrir mão da função de lidar com o setor financeiro da empresa, em passar essa responsabilidade para alguém que não fosse da família, em virtude da falta de confiança nos funcionários. Isso vai ao encontro do que propõe Chu e Wood (2008), ao afirmarem que a confiança dos gestores nas pessoas amigas e do ciclo familiar é maior do que a confiança depositada nos seus próprios funcionários. Porém, na pesquisa ficou evidente que os gestores conseguiram superar esse bloqueio e, atualmente, o setor financeiro é administrado por uma pessoa considerada pela empresa como qualificada e profissional.

Outra evidência está no fato de que a empresa estudada ainda apresenta fortes traços de uma gestão familiar, conquanto se nota o esforço dos seus gestores em adotarem algumas práticas de gestão profissional na organização, especialmente no Departamento de Compras, Central Unificada de Livros sistematizada, Setor de Recursos Humanos, Departamento Financeiro e Setor de Marketing.

Isso confirma a existência, na empresa pesquisada, do que afirma Bernhoeft (1989) sobre o fato de que, ao profissionalizar a gestão familiar, é importante considerar que ela não se refere exclusivamente aos aspectos organizacionais. Isto porque a mudança na estrutura hierárquica deverá, obrigatoriamente, ser precedida pela conscientização daqueles que detêm a propriedade e o poder, decorrente da necessidade imperativa da separação entre a família, a propriedade e a gestão.

Também pôde ser observado que, entre os quarenta funcionários da empresa, 82\% cursaram ou estão cursando o ensino superior, o que possibilita o crescimento da organização.

A pesquisa evidencia também que a empresa está passando por uma fase de reestruturação do seu modelo de negócios e em busca da profissionalização das etapas de processos de trabalho visando à reestruturação do seu modelo de gestão. Por outro lado, verificou-se que os gestores da empresa têm consciência de que é uma empresa familiar, e que mesmo assim acreditam que será por meio de práticas administrativas mais racionais e menos personalizadas, adotando uma política de qualidade expressa em manuais, normas e procedimentos, desenhando seus processos de trabalho e substituindo os métodos intuitivos por métodos impessoais e racionais, que conseguirão transformar a gestão do seu negócio.

\section{CONSIDERAÇÕES FINAIS}

Embora os resultados da pesquisa não devam ser generalizados, por se tratar de um estudo de caso único, não há, porém, em contrapartida, restrições para considerá-los exemplos de lições aprendidas, em virtude das características comuns compartilhadas pelas empresas familiares.

Nesse sentido, a pesquisa apresentada contribui para melhor entendimento do panorama das empresas familiares em início de profissionalização, ao apresentar o caso de uma pequena empresa do ramo de livros que atua sob os moldes da gestão familiar e que se esforça em profissionalizar-se.

Por outro lado, não seria ilógico pensar, ao se considerar as dificuldades comuns pelas quais costumam passar as pequenas e médias empresas, no que se refere ao tema estudado, que a presente pesquisa possa servir de benchmarking inicial para as empresas desse tipo.

A pesquisa possibilitou também elucidar que a profissionalização da gestão na empresa pesquisada faz-se por meio do empenho e esforço de seus proprietários em eliminar alguns traços da cultura familiar que dificultam a sua profissionalização e respectiva expansão.

Foram realizadas etapas distintas de estudo, entre elas, o estudo teórico sobre a temática proposta, o estudo no qual está inserida a empresa, a realização de entrevistas, visitas e observação no ambiente pesquisado.

A pesquisa bibliográfica, por sua característica exploratória, contribuiu para o melhor entendimento do tema central e dos outros diversos temas que estão correlacionados ao estudo. A revisão da literatura a propósito da gestão familiar e profissionalização serviu de base para o conhecimento da utilização sobre a sistemática organizacional. Além disso, a compreensão da abordagem teórica exposta neste estudo deu suporte ao entendimento do panorama de uma 
pequena empresa de gestão familiar, com forte intenção de completar a sua jornada rumo à total profissionalização, visando se tornar competitiva e ampliar a sua atuação no mercado. Assim, os resultados da pesquisa aplicada aos sócios gestores confirmaram que, para que a empresa alcance o seu objetivo de se profissionalizar é necessário também reavaliar seu atual modelo de gestão.

Com base no foco deste estudo, conclui-se que, considerando as particularidades da pequena empresa, da gestão familiar, da cultura da empresa, da visão de seus sócios gerentes e seus funcionários, e também da sua localização, faz-se necessária a profissionalização da gestão como critério de expansão mercadológica. Talvez o mais importante sobre isso seja o fato de seus gestores terem plena consciência dessa necessidade, buscando, realmente, trilhar o caminho da plena profissionalização.

\title{
FAMILY BUSINESS, YES! BUT WHAT IS THE PROBLEM, IF ITS MANAGEMENT IS PROFESSIONAL?
}

\begin{abstract}
This article aims to contribute to a better understanding of the reality of a Brazilian family owned business in transition from the family business administration model to a professional model of management. The company studied is a small Brazilian bookstore founded in 2000, in the state of Rio de Janeiro. It currently has six stores and one franchised store and a total of forty employees. The adminstration of the enterprise, which is basically familiar, needs a new management model to follow the pace of its expansion. The research method adopted was the case study with data collection through semi-structured interviews with company managers. The main results showed that the company is in the initial stages of a professionalization process. It needs, however, to accelerate this process by taking a proactive stance that supports the growth of the company.
\end{abstract}

Keywords: Small business. Family business. Professionalization. 


\section{REFERÊNCIAS}

AHMAD, Norzieiriani; AZIZAH, Omar; RAMAYAH, T. Consumer lifestyles and online shopping continuance intention. Business Strategy Series, Bradford, v. 11, n. 4, p. 227-243, 2010.

BARBOSA, Alexandre F. (Coord.). TIC Domicílios e empresas 2013. [2014]. Disponível em: <http:// www.cetic.br>. Acesso em: 2 mar. 2015.

BELLMAN, Steven; LOHSE, Gerald.L.; JOHNSON, Eric J. Predictors of online buying behavior. Communication of the ACM, New York, v. 42, n. 12, p. 32-38, 1999.

BLACKWELL, Roger D.; MINIARD, Paul W.; ENGEL, James F. Comportamento do consumidor. 9. ed. São Paulo: Cengage Learning, 2008.

CHIANG, Wey-yu Kevin; MONAHAN, George E. Managing inventories in a two enchant dual channel supply chain. European Journal of Operational Research, Amsterdan, v. 162, n. 2, p. 325-341, Apr. 2005.

DELOITTE. Serving the connected consumer: The Deloitte Consumer Review. [2011]. Disponível em :<http://www.deloitte.com>. Acesso em: 5 out. 2014.

DELOITTE. The new digital divide: Retailers, shoppers, and the digital influence factor. [2014]. Disponível em: <http://www.deloitte.com/us/Digitallnfluence>. Acesso em: 5 out. 2014.

DIAS FILHO, Jose Maria; CORRAR, Luiz João. Regressão Logística. In: CORRAR, L.J.; PAULO, E.; DIAS FILHO, J.M. (Coord.). Análise multivariada para os cursos de administração, ciências contábeis e economia. São Paulo: Atlas, 2014. cap. 5.

E-BIT. Pesquisa Webshoppers 29a edição. [2014]. Disponível em: <www.webshoppers.com.br>. Acesso em: 6 jun. 2014.

E-BIT. Pesquisa Webshoppers $31^{a}$ edição. [2015]. Disponível em: <www.webshoppers.com.br>. Acesso em: 24 fev. 2015.

FAILLA, Zoara (Org.). Retratos da leitura no Brasil. 3. ed. São Paulo: Instituto Pró Livro, 2012. Disponível em: <http://www.prolivro.org.br/ipl/publier4.0/dados/anexos/2834_10.pdf. >. Acesso em: 17 out. 2014.

FERGUSON, Douglas A.; PERSE, Elizabeth M. The World Wide Web as a Functional Alternative to Television. Journal of Broadcasting \& Electronic Media, Washington, v. 44, n. 2, p. 155-174, 2000.

GIL, Antonio Carlos. Métodos e técnicas de pesquisa social. 5. ed. São Paulo: Atlas, 1999.

GOLDKUHL, Lena. Multiple marketing channel conflict with a focus on the internet: A Dual Perspective. 2007. Ph.D. Dissertation (Ph.D.) - Lulea University of Technology, Sweden.

HAIR JR, Joseph F. et al. Análise multivariada de dados. 6. ed. São Paulo: Bookman, 2009.

HOFACKER, Charles F.; MURPHY, Jamie. Consumer web page search, clicking behavior and reaction time. Direct Marketing - An International Journal, Texas, v. 3, n. 2, p. 88-96, 2009.

HUANG, Echo. Use and gratification in e-consumers. Internet Research, Hackensack, NJ, USA, v. 18, n. 4, p. 405-426, 2008.

KACEN, Jacqueline J.; HESS. James D.; CHIANG, Wei-yu Kevin. Bricks or Clicks? Consumer attitudes toward traditional stores e online stores. Global Economics and Management Review, [S.I.], v.18, n. 1, p.12-21, Jan./Apr. 2013.

KOTLER, Philip; KELLER, Kevin Lane. Administração de marketing. 14. ed. São Paulo: Pearson Education do Brasil, 2012.

LEVIN, Aron M.; LEVIN, Irwin P.; HEATH, C. Edward. Product category dependent consumer preferences for online and offline shopping features and their influence on multichannel retail alliances. Journal of Electronic Commerce Research, California, USA, v. 4, n. 3, p. 85-93, 2003. 
LEVIN, Aron M.; LEVIN, Irwin P.; WELLER, Joshua. A. A multi-attribute analysis of preferences for online and offline shopping: differences across product, consumers, and shopping stages. Electronic Commerce Research, New York, v. 6, n. 4, p. 281-290, 2005.

LEVY, Michael; WEITZ, Barton. Administração de varejo. São Paulo: Atlas, 2000.

LOHSE, Gerald L.; BELLMAN, Steven; JOHNSON, Eric J. Consumer Buying Behavior on the Internet: Findings from Panel Data. Journal of Interactive Marketing, [S.I.], v. 14, n. 1, p. 15-29, 2000.

MORGADO, Maurício Gerbaudo. Comportamento do consumidor online: perfil, uso da Internet e atitudes. 2003. Tese (Doutorado) - Fundação Getúlio Vargas, São Paulo.

PREARO, Leandro Campi. $\mathbf{O}$ uso de técnicas estatísticas multivariadas em dissertações e teses sobre o comportamento do consumidor: um estudo exploratório. 2008. Dissertação (Mestrado) Faculdade de Economia, Administração e Contabilidade, Universidade de São Paulo, São Paulo.

ROSENBLOOM, Bert. Canais de marketing: uma visão gerencial. São Paulo: Atlas, 2009.

SELLTIZ, Claire et al. Métodos de pesquisa nas relações sociais. São Paulo: EPU, 1975.

SIEGEL, Sidney. Estatística não-paramétrica para as ciências do comportamento. São Paulo: McGraw-Hill, 1974.

SIEGEL, Sidney; CASTELLAN Jr., N. John. Estatística Não-Paramétrica para Ciências do Comportamento. 2. ed. Porto Alegre: Artmed, 2006.

TAKAHASHI, K. et al. Inventory control in a two-echelon dual-channel supply chain with setup of production and delivery. International Journal Production Economics, Amsterdan, n. 133, p. 403$415,2011$.

TO, Pui-Lai; LIAO, Chechen; LIN, Tzu-Hua. Shopping motivations on internet: a study based on utilitarian and hedonic value. Technovation, Essex, England, n. 27, p. 774-787, 2007.

YONGMEI Liu et al. Pricing decision under dual-channel structure considering fairness and freeriding behavior. Hindawi Publishing Corporation Discrete Dynamics in Nature and Society, New York, v. 2014, p. 1-10, May 2014. 